\title{
Cultural, Morphological and Pathogenic Variability in Alternaria cyamopsidis Causing Alternaria Blight of Clusterbean in Rajasthan
}

Jitendra Sharma, G.S. Rathore, S.L. Yadav, S.K. Goyal, Suresh Meena

10.18805/ag.D-5384

\begin{abstract}
Background: Alternaria cyamopsidis (Rang. and Rao) causes Alternaria blight of clusterbean and it is one of the significant disease of clusterbean. Studies were conducted to compare the Cultural, morphological and pathogenic variability among ten isolates of Alternaria cyamopsidis from clusterbean, in five districts of Rajasthan viz., Bikaner, Barmer, Churu, Hanumangarh and Jaipur.

Methods: During 2016-17 exhaustive survey was conducted in clusterbean growing areas of Rajasthan and collected diseased samples of clusterbean caused by Alternaria. All the samples were processed for isolation, purification, and their pathogenicity was proved in cagehouse and laboratory and standard methods were adopted for cultural and morphological variability study.

Result: All the isolates showed variation in their morphological characters, i.e., colony color and shape; conidial number, size, width, length, shape and septation on PDA. Out of ten isolates two isolate, viz., AlcyJp1 and AlcyJp2 showed maximum colony diameter 89.50 and $86.30 \mathrm{~mm}$, respectively. All the isolates varied in their spore length and width and virulent on the tested variety of clusterbean for virulence. AlcyJp1 was the most virulent and produced maximum (65.50\%) disease intensity, followed by AlcyJp2 isolate (61.22\%).

Key words: Alternaria blight, Alternaria cyamopsidis, Clusterbean, Morphological, Pathogenic variability.
\end{abstract}

\section{INTRODUCTION}

In India, pulses have been described as a 'Poor man's meat and rich man's vegetable.' Clusterbean [Cyamopsis tetragonaloba (L.) Taub.], commonly called "Guar," is an important arid legume crop. Clusterbean is being grown in India since ancient times. However, it is believed to be of African origin (Vavilov, 1951). Traditionally, clusterbean is produced for different purposes viz., vegetable (pods), green fodder, green manure, straw and seed production.

Tendergreen guar pods are an essential source of nutrition for human beings and animals. India's contribution is around $75-80$ per cent ofthe world's total production, followed by Pakistan and others (Tripathy and Das, 2013). India stands in the first position in the world concerning the area and production of guar.In India, this crop is mainly grown in the states of Rajasthan, Haryana, Gujarat, Punjab, U.P. and M.P. In Rajasthan, it is primarily grown in Bikaner, Jaisalmer, Barmer, Churu, Hanumangarh, Sriganganagar, Jodhpur, Nagaur, Sikar, Jhunjhunu and Jaipur districts. The production of clusterbean in terms of grain and fodder is limited primarily due to the Alternaria blight disease of clusterbean in Northern India and Rajasthan (Rangaswami and Rao, 1957; Meena et al., 2012). The maximum severity of the blight takes place between bloom and pod set. Higher yield losses (43-78\%) were recorded when leaves were infected at the seedling stage than at the old stage (Sharma, 1981 and Anonymous, 2013-14). Very little information on morphological and pathogenic variability in Alternaria cyamopsidis of clusterbean is available from India. Variability studies give an idea about pathogenic variability among
Department of Plant Pathology, SKN College of Agriculture, SKN Agriculture University, Jobner-303 329, Jaipur, Rajasthan, India.

Corresponding Author: S.K. Goyal, Agriculture Testing Centre, Government of Rajasthan, Ajmer-305 001, Rajasthan, India.

Email: skgoyal.skncoa@sknau.ac.in

How to cite this article: Sharma, J., Rathore, G.S., Yadav, S.L., Goyal, S.K. and Meena, S. (2022). Cultural, Morphological and Pathogenic Variability in Alternaria cyamopsidis Causing Alternaria Blight of Clusterbean in Rajasthan. Agricultural Science Digest. DOI: 10.18805 /ag.D-5384.

Submitted: 20-05-2021 Accepted: 07-12-2021 Online: 11-01-2022

Alternaria cyamopsidis and such information will be helpful to develop resistant cultivars to the disease. Keeping in view of the variations in disease intensity of different areas, studies have been conducted to ascertain the cultural, morphological and pathogenic variations among different isolates of $A$. cyamopsidis from different regions of Rajasthan.

\section{MATERIALS AND METHODS}

\section{Survey and collection}

Survey of major clusterbean growing areas of Bikaner, Hanumangarh, Barmer, Churu and Jaipurdistricts of Rajasthan was conducted at the pod formation stage of the crop to record Alternaria blight intensity and to collect disease samples. The diseased samples collected during the survey were brought to the laboratory in paper bags for further studies. 


\section{Isolation, purification and identification}

To ascertain the variability among the isolates of $A$. cyamopsidis, cultural and morphological studies were conducted on potato dextrose agar (PDA) medium. Isolations were made from the infected plants showing typical symptoms (Concentric rings) of Alternaria blight. Ten isolates of $A$. cyamopsidis isolated from clusterbean leaves, collected from different locations of Bikaner, Barmer, Churu, Hanumangarh, and Jaipur districts of Rajasthan and designated as AlcyBk ( $A$. cyamopsidis Bikaner isolate), $\operatorname{AlcyBr}(A$. cyamopsidis Barmer isolate), AlcyCh ( $A$. cyamopsidis Churu isolate), AlcyHg (A. cyamopsidis Hanumangarh isolate) and AlcyJp (A. cyamopsidis Jaipur isolate), respectively. Small pieces of the leaves of the clusterbean plant were cut from the diseased portion along with some healthy tissues, surface-sterilized for 1-2 minutes in 1.0 per cent Sodium hypochlorite solution with three piles of washing by sterilized distilled water. These bits were transferred aseptically to potato dextrose agar in Petri plates separately. Incubation was done at $25 \pm 1^{\circ} \mathrm{C}$ for seven days. Sub-culturing from uncontaminated peripheral growth was made on PDA slants.

For the purification of the fungus, a single spore isolation technique was used. After sporulation, the conidial suspension was made in sterile water. The dilution was adjusted so that in one loop full, 20-25 conidia could be counted under the low power objective. One such loop full was mixed with $20 \mathrm{ml}$ melted and sterilized agar $(2 \%)$ and poured in sterile Petri plates. After 12 hours of incubation at $25 \pm 1^{\circ} \mathrm{C}$, the single germinating conidium was cut with the help of a dummy objective and transferred to PDA slants. They were subsequently allowed to grow and sporulate. Monoconidial culture established in this way was maintained by periodical transfer on PDA slants. After purification, the fungus was allowed to sporulate. The pure sporulating culture was identified based on morphological characters and literature basis.

\section{Cultural and morphological variability}

Single spore cultures of different isolates established and maintained (Table 1) on potato dextrose agar (PDA) were studied for their cultural and morphological characters. Seven days old culture of each isolate was inoculated (5 $\mathrm{mm}$ diameter disc) separately on PDA and incubated at $25 \pm 1^{\circ} \mathrm{C}$. After seven days of incubation, radial growth of fungal mycelium, colony characters of each isolate, such as colony growth and colony colour. The measurements of the size (length and width) of conidia and septation were taken with the help of fluorescence microscopy.

\section{Pathogenic variability}

To test the pathogenic variability among ten isolates, apparently healthy surface-sterilized cluster bean seeds (Variety RGC-936) were taken. Seeds were sown at five cm depth in micro plots with three replications of each isolate. Spore suspension of each isolate was prepared in sterilized distilled water separately by blending seven days old fungal culture in pestle and mortar and filtered through cheesecloth, spore suspension was further diluted to $1 \times 10^{5} \mathrm{spores} / \mathrm{ml}$ and 20 days old clusterbean plant were separately inoculated with each isolate and observations on disease intensity were recorded after 20 days of inoculation as per 0-5 rating scale (Table 2 and Plate 1). Randomly selected ten plants from each field were rated as per the following description and per cent disease intensity (PDI) on foliage was calculated using the formula of McKinney (1923) and Meena et al. (2012).

Alternaria blight disease intensity $(\%)=$

$\frac{\text { Sum of all numerical ratings }}{\underset{\text { Total number of }}{\text { plants observed }} \times \text { Maximum disease }} \times 100$

\section{RESULTS AND DISCUSSION} Survey and collection

A roving survey was conducted during Kharif 2016-17 in five clusterbean growing districts of Rajasthan viz., Bikaner, Barmer, Churu, Hanumangarh and Jaipur. The survey was carried out in two villages from one tehsil of each district. During the survey, discussions were held with the farmers concerned about the disease's occurrence and incidence. During the survey,the disease intensity of Alternaria blight of clusterbean was recorded from 21.17 to 40.17 per cent in all surveyed areas of Rajasthan.

\section{Isolation, purification and identification}

Isolation of the pathogen from diseased plants of clusterbean collected from farmers' fields was done on potato dextrose agar (PDA) medium. After seven days of incubation at $25 \pm 1^{\circ} \mathrm{C}$, the growth of the fungus was obtained. Pure culture of the pathogen, obtained by single sporing on water agar, yielded Alternaria cyamopsidis. The colonies were profused, dark-blackish brown or greyish black velvety. Hyphae were branched, septate, hyaline at first, later turn brown-black to olivaceous - black or brown in colour. Hypha is 2.81 to 4.45 $\mu$ width. Conidiophores were arising in groups, greyish olive in color, septate, geniculate, and prominent scar at each geniculation.

Table 1: The coding for each isolates were given as under.

\begin{tabular}{lccc}
\hline District & Tehsil & Village & Isolate no. \\
\hline Bikaner & Bikaner & Palana & AlcyBk1 \\
Bikaner & Bikaner & Rashisar & AlcyBK2 \\
Barmer & Pachpadra & Budhiwara & AlcyBr1 \\
Barmer & Pachpadra & Jhagsa & AlcyBr2 \\
Churu & Rajgarh & Daderwa & AlcyCh1 \\
Churu & Rajgarh & Chandkhoti & AlcyCH2 \\
Hanumangarh & Bhadra & Bhadra & AlcyHg1 \\
Hanumangarh & Bhadra & Gogamedi & AlcyHg2 \\
Jaipur & Phulera & Tyod & AlcyJp1 \\
Jaipur & Phulera & Khatwadi & AlcyJp2 \\
\hline
\end{tabular}


Conidia were smooth to echinulated, greyish olive coloured, straight, some time with a curved beak, obclavate, borne singly or in chains of upto three conidia, muriform with measuring length $95.433-210.791 \mu(\mathrm{Av} .173 .402 \mu) \mathrm{x}$ width $16.135-26.543$ (Av. $20.682 \mu$ ). The conidial body tapers abruptly to the junction with the beak. The conidial beak is filiform, septate, lighter in colour as compared to the conidial body, 0-3 septate. The beaks were usually long, varying $1 / 2$ to $1 \frac{1}{2}$ times the length of conidium. The beak is bulbous at the base and rapidly narrowing towards the apex. On the basis of measurement and other morphological characters with the help of fluorescence microscopy and

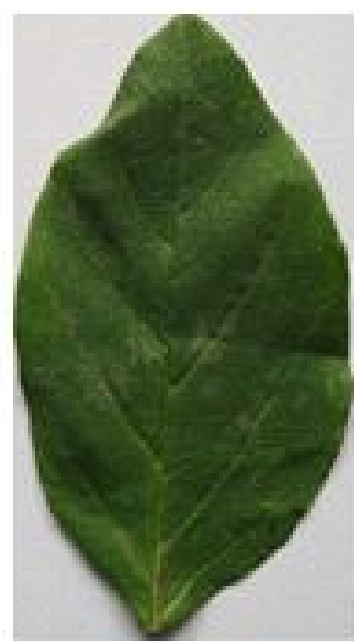

Scale 0

(No disease)

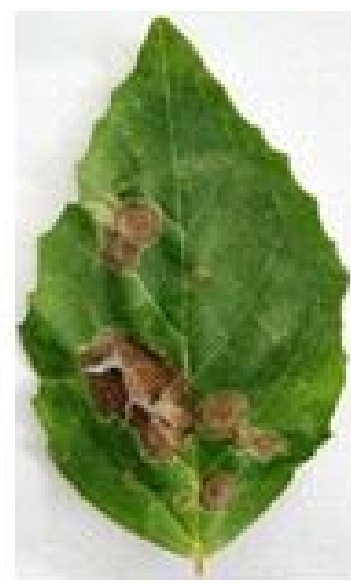

Scale 3

$(10.1-25 \%$ area affected)

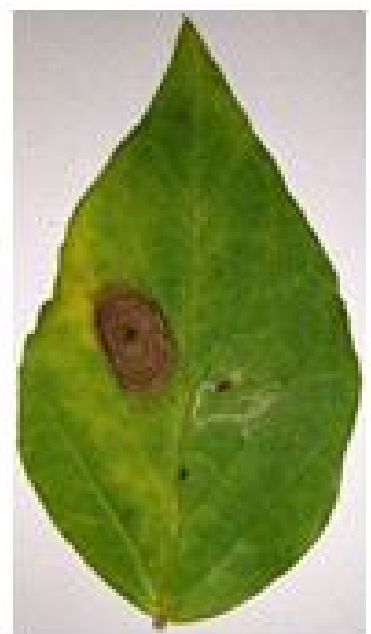

Scale 1

(0.1-5\% area affected)

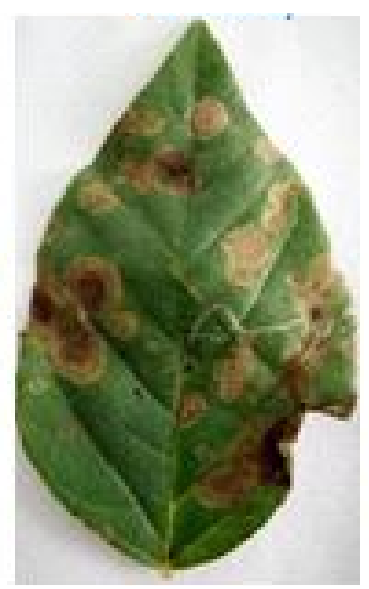

Scale 4

(25.1-50\% area affected)

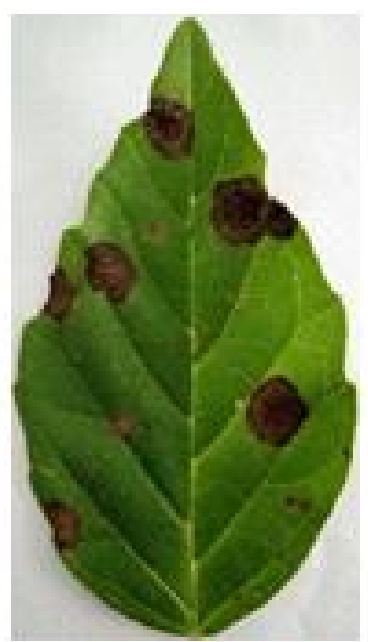

Scale 2

(5.1-10\% area affected)

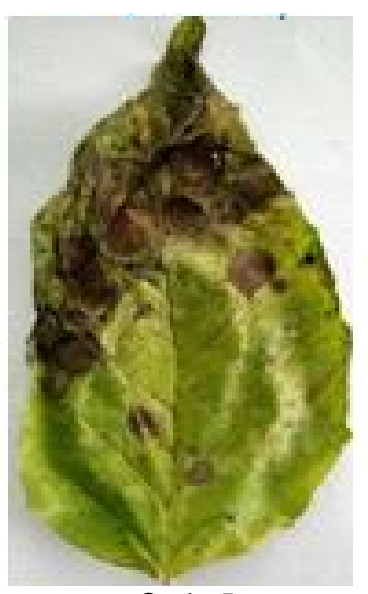

Scale 5

$(>50 \%$ area affected)

Plate 1: Alternaria blight disease rating scale on clusterbean.

Table 2: Alternaria blight disease rating scale on clusterbean.

\begin{tabular}{lll}
\hline $\begin{array}{l}\text { Disease } \\
\text { rating /grade }\end{array}$ & $\begin{array}{l}\text { Per cent leaf } \\
\text { area affected }\end{array}$ & Description \\
\hline 0 & - & Healthy \\
1 & $0.1-5.0$ & One or two scattered lesion or spots on leaves \\
2 & $5.1-10.0$ & moderate number of lesions or spots on leaves \\
3 & $10.1-25.0$ & Moderate infection, abundant lesions or spots on leaves \\
4 & $25.1-50.0$ & Heavy infection, abundant lesions or spots on leaves \\
5 & $>50.0$ & Very heavy infection, lesions or spots abundant on leaves, plant prematury, dry or killed by the disease \\
\hline
\end{tabular}


based on literature, the pathogen was identified as Alternaria cyamopsidis Rang. and (Rangaswami and Rao, 1957 and Orellana and Simmons, 1965). Similarly, isolation of pathogen on PDA was reported by Singh and Prasad (1973). The cultural characters of Alternaria cyamopsidis normal longitudinal and transverse septa. The findings are in confirmation with those of Rangaswami and Rao (1957) and Orellana and Simmons (1965).

\section{Cultural and morphologicalvariability}

The cultural characteristics such as shape, colour and size of the colony and morphological features such as the size of conidia and septation were recorded for different isolates of $A$. cyamopsidis by growing them on PDA medium.

The results showed that isolates of $A$. cyamopsidis differ in their colony characters, colony colour and colony diameter (Table 3). Out of ten isolates, AlcyJp1 (collected from Tyod village of Phulera tehsil of Jaipur district) showed maximum colony diameter (89.50 followed by AlcyJp2 $(86.30 \mathrm{~mm})$, AlcyCh1 (85.60 mm), AlcyHg2 (83.50 mm), AlcyHg1 (82.30 $\mathrm{mm})$, AlcyCh2 (80.10 mm), AlcyBr1 (76.30 mm), AlcyBk1 $(74.50 \mathrm{~mm})$ and AlcyBk2 $(65.80 \mathrm{~mm})$ while isolate AlcyBr2 showed minimum colony diameter $(60.50 \mathrm{~mm})$ after seven days of incubation.Isolate AlcyJp1 showed greyish white colony colour, fluffy white growth with a smooth greyish margin. Isolate AlcyJp2 showed gray center, blackish gray velvety growth with smooth grayish margin but isolate AlcyBr2 showed grayish centre, white, black cottony growth with the white periphery.

Morphological observations of each isolate revealed that all the isolates vary in their spore length and width. In general, spore length and width were found in between 95.433 to $210.791 \mu$ and 16.135 to $26.543 \mu$, respectively. In contrast, the number of horizontal and vertical septa varied between 6 to 8 and 2 to 5 , respectively (Table 2). The AlcyJp1 isolate showed maximum length and width of conidia $210.791 \mu$ and $26.543 \mu$, respectively.whereas isolate AlcyBk2 showed minimum length and width of conidia $95.433 \mu$ and $16.135 \mu$, respectively.

The maximum number of horizontal septa (8) were observed in AlcyJp1, AlcyJp2, AlcyHg1, AlcyHg2 and AlcyCh2 isolates and minimum number in AlcyBk2 and AlcyCh1 isolates, respectively. Vertical septa were maximum (5) in AlcyJp1 isolate and minimum (2) in AlcyBk1, AlcyBk2, AlcyBr1 and AlcyCh1 isolates.

\section{Pathogenic variability}

Results presented in Table 4 revealed that all the isolates were pathogenic to clusterbean and produced characteristic symptoms of the disease. The mean per cent disease intensity was highest (63.38\%) with Jaipur isolates followed by Hanumangarh isolates $(56.50 \%)$, Barmer isolates $(44.52 \%)$ and Churu isolates $(38.74 \%)$. The minimum mean per cent disease intensity was in Bikaner (36.51\%) isolates. The overall mean disease intensity of the five districts was 47.93 per cent.

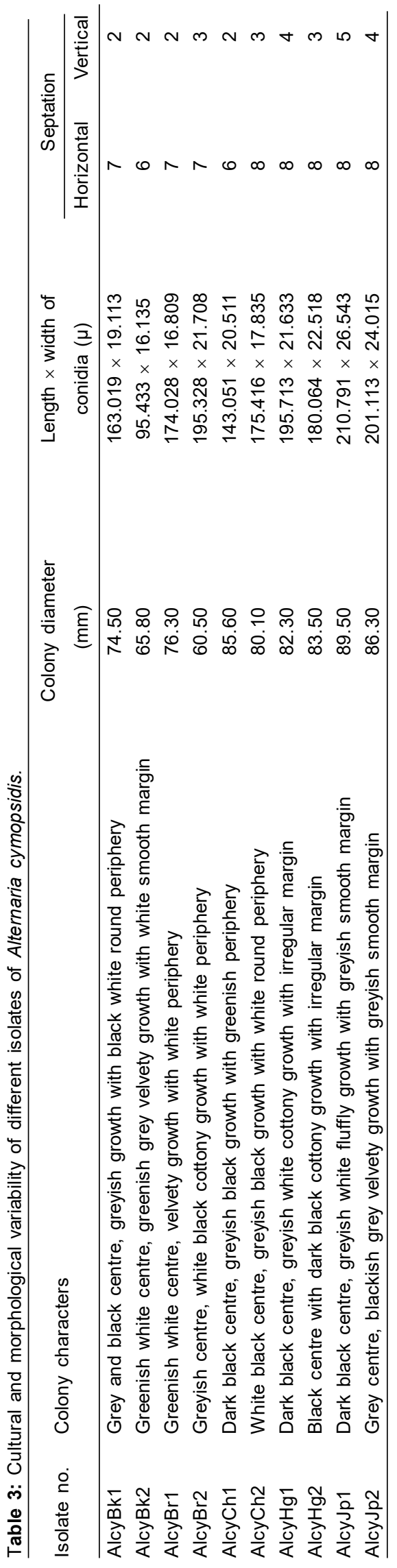


Among these isolates AlcyJp1 was found to be most virulent and produced maximum (65.50\%) disease intensity followed by AlcyJp2 isolate $(61.22 \%)$, AlcyHg1 isolate $(58.66 \%)$, AlcyHg2 isolate $(54.33 \%)$, AlcyBr2 isolate $(46.71 \%)$, AlcyBr1 isolate $(42.33 \%)$, AlcyCh2 isolate $(40.31 \%)$, AlcyBk1 isolate $(38.33 \%)$ and AlcyCh1 isolate (37.17\%) whereas AlcyBk2 isolate was found less virulent with minimum disease intensity (34.69\%).

Phenotypic, Cultural and pathogenic variability among isolates of different species of Alternaria has also been reported by several workers (Sharma and Pandey, 2012, Shekhawatet al., 2013, Meena et al., 2014, Singh et al., 2014and Nikamet al., 2015).

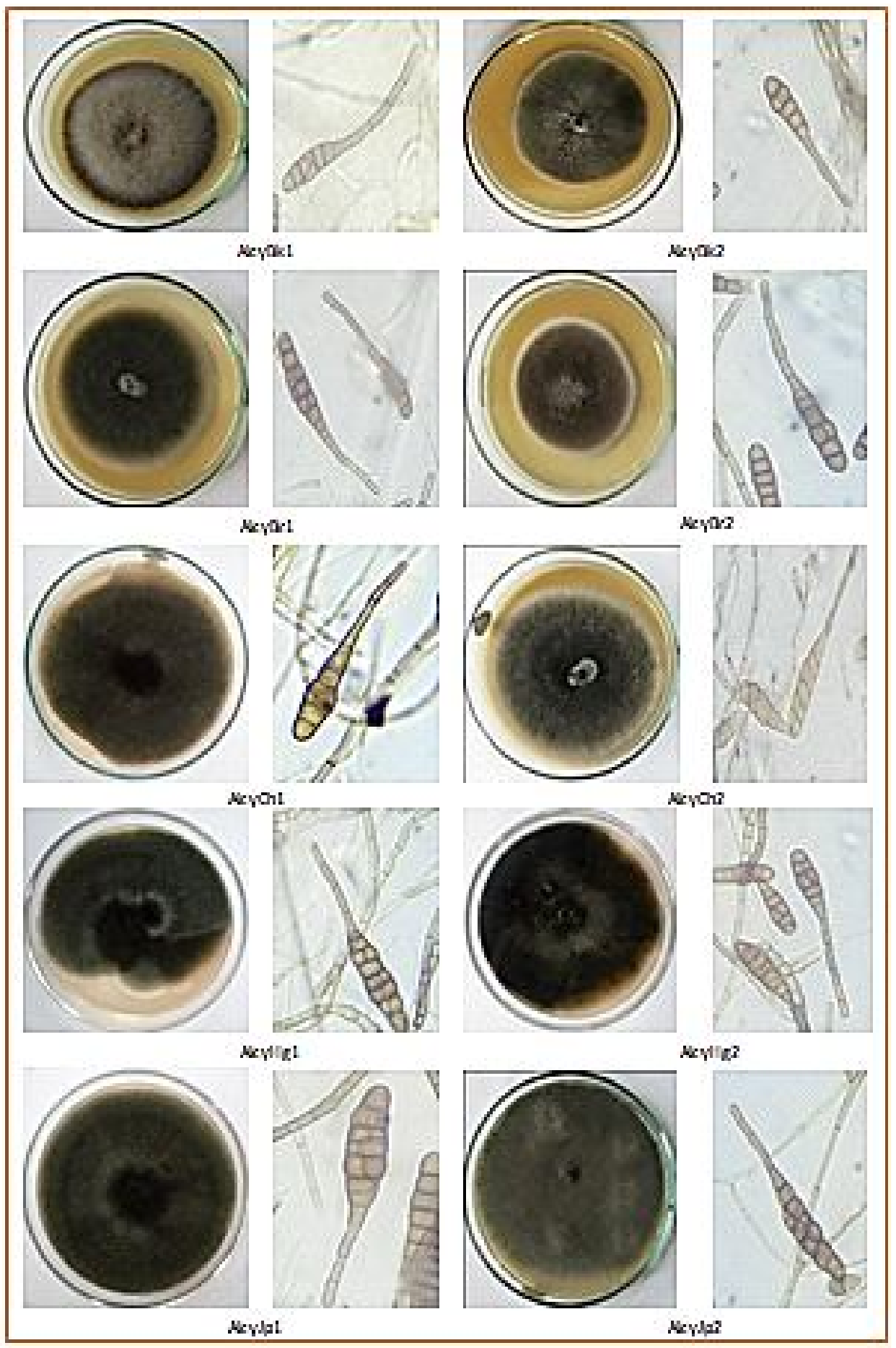

Plate 2: Cultural amd morphological variability of different isolates of Alternaria cyamopsidis. 
Cultural, Morphological and Pathogenic Variability in Alternaria cyamopsidis causing Alternaria Blight of Clusterbean in Rajasthan

Table 4: Pathogenic variability of different isolates of Alternaria. cymopsidis.

\begin{tabular}{lcccc}
\hline Isolate No. & District & Tehsil & Village & Disease intensity (\%) \\
\hline AlcyBk1 & Bikaner & Bikaner & Palana & 38.33 \\
AlcyBk2 & Bikaner & Bikaner & Rashisar & 34.69 \\
& & & Mean & $\mathbf{3 6 . 5 1}$ \\
AlcyBr1 & Barmer & Pachpadra & Budhiwara & 42.33 \\
AlcyBr2 & Barmer & Pachpadra & Jhagsa & 46.71 \\
& & & Mean & $\mathbf{4 4 . 5 2}$ \\
AlcyCh1 & Churu & Rajgarh & Daderwa & 37.17 \\
AlcyCh2 & Churu & Rajgarh & Chandkhoti & 40.31 \\
& & & Mean & $\mathbf{3 8 . 7 4}$ \\
AlcyHg1 & Bhadra & Bhadra & 58.66 \\
AlcyHg2 & Hanumangarh & Bhadra & Gogamedi & 54.33 \\
& Hanumangarh & & Mean & $\mathbf{5 6 . 5 0}$ \\
Alcyjp1 & & Tyod & 65.50 \\
AlcyJp2 & Jaipur & Phulera & Khatwadi & 61.22 \\
& Jaipur & & Mean & $\mathbf{6 3 . 3 8}$ \\
\hline
\end{tabular}

\section{CONCLUSION}

The results on cultural, morphological and pathogenic variability among different isolates of $A$. cyamposidis, collected from various locations in five districts of Rajasthan, showed that isolates differed in their colony characters, diameter and septation.

Isolate (AlcyJp1) from Jaipur district showed maximum mycelial growth $(89.50 \mathrm{~mm})$, maximum length $x$ width of conidia $(210.791 \times 26.543 \mu)$,the diameter of conidia LxW $(5595.026 \mu)$, top horizontal (8) and vertical (5) septa. It was found most virulent and produced maximum (65.50\%) disease intensity.

Isolate (AlcyBr2) from the Barmer district showed minimum mycelial growth with a colony diameter of 60.50 $\mathrm{mm}$. In general conidial length and width were observed in between 95.433 to $210.791 \mu$ and 16.135 to $26.543 \mu$, respectively. All the isolates were found pathogenic to clusterbean and produced characteristic symptoms of the disease. Among these isolates, AlcyJp1 was found to be most virulent and had maximum $(65.50 \%)$ disease intensity, followed by AlcyJp2 isolate (61.22\%). The highest mean per cent disease intensity was with AlcyJp1 isolate (63.38\%) and lowest with AlcyBk $_{2}(34.69 \%)$.

\section{REFERENCES}

Anonymous (2013-14). An analysis of performance of guar crop in India. CCS National Institute of Agricultural Marketing, Jaipur.

McKinney, H.H. (1923). Influence of soil temperature and moisture on infection of wheat seedling by Helminthosporium sativum. Journal of Agricultural Research. 26: 195-217.

Meena, A.K., Godara, S.L., Gangopadhyay, S., Jatav, R.S. and Meena, V.R. (2012). Progression of Alternaria blight on different varieties of clusterbean in relation to weather parameters. Journal of Plant Development Sciences. 4(4): 619-627.
Meena, R.K., Sharma, S.S. and Singh, S. (2014). Studies on variability in Alternaria alternate (Keissler) causing leaf blight of isabgol (Plantago ovata). SAARC Journal of Agriculture. 12(2): 63-70.

Nikam, P.S., Suryawanshi, A.P. and Chavan, A.A. (2015). Pathogenic, cultural, morphological and molecular variability among eight isolates of Altenaria solani, causing early blight of tomato. African journal of Biotechnology. 14(10): 872-877.

Orellana, R.G. and Simmons, E.G. (1965). Alternaria blight of guar in the United States. Plant Disease Reporter. 27: 129-131.

Rangaswami, G. and Rao, A.V. (1957). Alternaria blight of clusterbean [Cyamopsis tetragonoloba (L.) Taub]. Indian Phytopathology. 10: $13-18$.

Sharma, S.R. (1981). Yield loss in clusterbean caused by Alternaria cyamopsidis. Vegetable Science. 8(1):58-63.

Sharma, S. and Pandey, R.N. (2012). Variability among isolates of Alternaria burnsii from cumin (Cuminum cyminum L.). Bioinfolet. 9(4A): 610-616.

Shekhawat, N., Trivedi, A., Sharma, S.K. and Kumar, A. (2013). Cultural, morphological and pathogenic variability in Alternaria burnsii causing blight of cumin. Jr. of Mycol. and PI. Patho. 43(1):80-83.

Singh, A., Singh, V. and Yadav, S.M. (2014). Cultural, morphological and pathogenic variability of Alternaria solani causing early blight in tomato. Plant Pathology Journal. 1-6.

Singh, S.D. and Prasad, R. (1973). Studies on physiology and control of Alternaria cyamposidis the incitant of blight disease of guar. Indian J. of Mycol. and PI.Patho. 3:33-39.

Tripathy, S. and Das, M.K. (2013). Guar gum: present status and applications. Journal of Pharmceutical and Scientific Innovation. 2: 24-28.

Vavilov, N.I. (1951). Phytogeographic basis of plant breeding, the origin, variation, immunity and breeding of cultivated plants. Chronica Botanica. 13: 1-366. 